\title{
Installation, Maintenance and Repair Occupations
}

National Cancer Institute

\section{Source}

National Cancer Institute. Installation, Maintenance and Repair Occupations. NCI

Thesaurus. Code C97636.

A class of professional or vocational positions of employment that involve installation, maintenance or repair. 